\title{
Guiding Interventions in a Multi-Organisational Context: Combining the Viable System Model and Hierarchical Process Modelling for use as a Problem Structuring Method
}

\begin{abstract}
This paper describes the development and application of an innovative problem structuring method to guide interventions in the way in which the UK Ministry of Defence delivers infrastructure projects and services. This method uses an adaptation of the Viable System Model to structure a set of stakeholder assessments that leads to the building of a Hierarchical Process Model. The resultant model, which appears readily transferrable to other multi-organisational contexts, comprehensively represents the functions required for a specified system to be effective in its environment and affords insight into the processes and capabilities that require intervention - either to increase performance (addressing weaknesses) or to increase understanding (addressing uncertainty). The paper also describes a number of methodological learning points identified through the use of a structured approach to evaluation which again appear to be readily transferrable to other multi-organisational contexts.
\end{abstract}

Key words: Problem Structuring Methods, Systems, Organizational Studies

\section{Introduction}

This paper describes how two established systems methods - the Viable Systems Model (VSM) and Hierarchical Process Modelling (HPM) - were adapted, combined and applied in order to guide intervention in a multi-organisational context. The work was conducted from January to July 2014 by practitioners at the Defence Science and Technology Laboratory (Dstl) in collaboration with researchers at the University of Bristol in support of Ministry of Defence (MOD) decision-making. The aim of the work was to identify the strengths, weaknesses and uncertainties associated with the operation of the Defence Infrastructure Organisation (DIO) in the context of the wider MOD enterprise, together with candidate actions for intervention.

The DIO is the part of the MOD that is responsible for building, maintaining and servicing the infrastructure needed to support the UK's Armed Forces and MOD as a whole. It enables MOD personnel - military and civilian - to live, work, train and deploy both in the UK and overseas. The DIO was created in 2011 in response to recommendations within Lord Levene's review of Defence to “coherently manage delivery against MOD's infrastructure requirements" (Levene, 2010). In order to drive further efficiency and effectiveness, in 2014 MOD decided to introduce a strategic business partner within the DIO to act as the senior management team and inject knowledge and expertise developed in the private sector. 
As part of the preparations for this introduction Dstl were tasked to assess the delivery of infrastructure services within the MOD in order to identify major strengths, weaknesses, uncertainties and to highlight aspects that should be addressed as part of a broad reform programme (Defence Infrastructure Systems Programme). Whilst the task was initially focussed on the DIO, the scope was expanded to include the elements of MOD Head Office that provide governance for the operation of the DIO ('Governor' role) and the Armed Forces and other elements of MOD such as Defence Equipment and Support that provide infrastructure requirements for the DIO to deliver against ('Customer' role). This broader scope of inquiry was referred to as the Infrastructure Delivery System.

The paper proceeds with a description of the method design (that cites relevant literature throughout and makes clear how prior work has influenced this design) together with a description of how the method was applied (2. Method Design and Literature Review). It then describes the results and reflects upon their impact (3. Results) before setting out four key methodological learning points that appear readily transferrable to other multi-organisational contexts (4. Discussion). The paper concludes by highlighting how this work has contributed to the field of problem structuring research and practice (5. Conclusions).

\section{Method Design and Literature Review}

This work is at its heart participatory and its purpose was to improve the organisational outcome for decision makers - and all stakeholders - dealing with a complex problem context. Action Research is then the obvious research paradigm for positioning this work and the motivation for the critical reflection on the efficacy of the approach reported in this paper. However, the authors step back from the emancipatory view of action research articulated by researchers such as Reason and Bradbury (cited in Brydon-Miller et al., 2003, p10-11). Whilst the knowledge created by this work is undoubtedly to the benefit of the organisation, and in terms of methodology of likely value to other organisations with similar problem contexts, the question of wider value to the community at large is a political one beyond the evaluative scope of our work (ibid p11). However, it is accepted that the knowledge created through action research is socially constructed (ibid p11). How this knowledge comes about is thus a process of imposing certain critical elements in the construction of the research design suited to this type of situated research.

Checkland and Holwell (1998, p12) citing Argyris et al. (1985) provide us with the following constitutive elements for Action Research: "a collaborative process between researchers and people in the situation, a process of critical inquiry, a focus on social practice, and a deliberate process on reflective learning." Based on the development of Soft Systems Methodology (SSM) as a programme 
of Action Research, Checkland and Holwell then take these elements to state a regular framework for knowledge creation through action research as "Particular linked ideas F are used in a methodology $M$ to investigate an area of interest $A$. Using the methodology may then teach us not only about $A$ but also about the adequacy of $F$ and $M$." This approach has provided the basis for action research design in a number of recent studies (Tavella and Papadopoulos, 2015; Espinosa et al., 2014; Espinosa and Walker 2013; Franco and Lord, 2011).

Using this FMA formulation of an action research project the Area of concern was finding ways to assess and monitor the health of the Infrastructure Delivery System (centred on the operation of the DIO) and to propose actions based upon shortfalls identified. The following sections describe the Framework of ideas upon which the Methodology drew in order to develop and apply the method.

\section{$\underline{2.1 \text { Framework of Ideas }(\mathrm{F})}$}

The methodology draws upon established models (VSM and HPM) and integrates them together in a multi-methodology to establish a PSM suitable for application to this particular area of concern. This sub-section describes each of these four ideas - PSMs, VSM, HPM and multi-methodology beginning with an overview of PSMs.

\subsubsection{Problem Structuring Methods}

PSMs were first recognised as a distinct field of Operational Research (OR) that "provide decision makers with systematic help in identifying an agreed framework for their problem" in the mid-1990s (Rosenhead, 1996). Prior to this a number of methods were developed independently in response to the inability of traditional OR methods to adequately address messy, wicked, swampy, problems (respectively Ackoff, 1977 and Ackoff, 1979; Rittel and Webber 1973; Schon, 1987). The three most prominent of these methods comprise: SSM (Checkland, 1981), Strategic Choice Analysis (Friend and Hickling, 1987), Strategic Options Development and Analysis (Eden, 1990).

With much development and reflection since, summarised by Ackermann (2012), Eden and Ackermann (2006), Mingers (2011), Mingers and Rosenhead (2004), Rosenhead (2006) and White (2009), recent work has proposed a Generic Constitutive Definition (GCD) for PSMs (Yearworth and White, 2014). Whilst intended to help with identifying non-codified uses of PSMs to aid data collection and case study analysis, the nine aspects of the GCD can also reasonably be used as a set of design guidelines for PSMs. These nine aspects comprise: (1) Improvement activity; (2) Systemic approach; (3) Adaptation / Creativity; (4) Methodological lessons; (5) Worldviews; (6) Messiness; (7) Interactive / Iterative / Therapeutic; (8) Subjectivity; and (9) Limits. This paper uses these nine aspects as a basis for design and critique. 
Whilst PSMs have traditionally been used in support of empowered decision-makers, there is increasing interest in how these methods can be used to support decision making in multiorganisational settings in which there exists a "lack of history, conflicting goals, complex politics and power, multiple roles, and [uncertainty over] who the client is" (Ackermann, Franco, Gallupe and Parent, 2005). These issues were all manifest in this project and our method design was in-part guided by the success reported in recent case study accounts of using PSMs to address these issues (Ackermann et al., 2005; Franco, 2006; Franco 2007; Eden and Ackermann, 2014), principally through the conduct of effective problem structuring, creation of shared understanding, and engendering of high levels of supportability and subsequent ownership of the commitments.

\subsubsection{The Viable Systems Model}

Stafford Beer developed the VSM (Beer, 1972; 1979; 1985) by applying cybernetic theory (regarding the flow and use of information for regulation and control) to the management of organisations. He established that the viability of an organisation to exist in its environment is dependent on the capacity of, and strong links between, five key system elements - Identity (S5), Intelligence (S4), Control (S3 including Audit S3*), Coordination (S2) and Operations (S1). These 'invariances' provide a functional framework for the design of a new system and/or the assessment of an existing system. It can be applied recursively to model organisational scale and complexity.

The VSM "is a model of the necessary and sufficient conditions for the viability of systems" (Reynolds and Holwell, 2010) and "offers an insightful framework for thinking differently about organizations" (Brocklesby and Cummings, 1996). It is a very well-established method that continues to be used to support the review of existing organisations and/or the design of new organisations in domains as diverse as disaster response (Preece et al. 2013), sustainable development (Espinosa and Walker, 2013), combatting transnational organised crime (Brocklesby, 2012), supply chains (Hildbrand and Bodhanya, 2014), local food networks (Tavella and Papadopoulos, 2015) and management of large multi-national corporations (Espinosa et al., 2014).

Whilst Jackson maps the VSM to the complex-unitary box on his System of Systems Methodology (SoSM) along with System Dynamics and Complexity Theory he does allow that "the functionalist paradigm certainly does not exhaust the possibilities opened up by the VSM" (Jackson, 2001). Methods for the application of VSM in the functionalist sense have been developed - see Viable Systems Diagnosis (Flood and Jackson, 1991) and the Viplan method (Espejo et al., 1999) - where the researchers act in 'expert' mode (Franco and Montibeller, 2010) to compare the reality of the problem situation to VSM theory and recommend actions accordingly. The VSM has also been used in an interpretivist sense. For example, a self-organising group used VSM as a hermeneutical tool with the help of consultants acting in a 'facilitator' mode to understand their organisational (dis)function, identifying actions to improve their effectiveness and viability and to follow through 
building on the consensus that has been established (Espinosa and Walker, 2013). A number of other examples of the use of the VSM in this way have been reported (Brocklesby, 2012; Tavella and Papadopoulos, 2014; and Espinosa et al., 2014) and together these suggest ways in which the VSM supplies the necessary systemic approach for a PSM in the sense of the GCD by using "systems ideas (including boundary, hierarchy, communication and control), which (i) are appropriate to context, (ii) theoretically adequate, and (iii) supported by appropriate systems modelling" (Yearworth \& White, 2014).

However, the use of the VSM to support problem structuring raises a number of questions of its suitability in the sense meant by the GCD (Yearworth and White 2014, Table 1). Whilst it directly addresses the limitations (aspect 9 of the GCD) of other system modelling approaches in that it provides "adequate conceptual terminology" about questions such as requisite variety and directly supports action to improve (aspect 1), and is without doubt a systemic approach as mentioned (aspect 2), more work is needed to understand how the VSM allows methodological learning (aspect 4), supports accommodation of worldviews (aspect 5) and its interactive/iterative use (aspect 7). Furthermore, its cognitive accessibility as a systems modelling approach (aspect 2) and its apparent immutability as a model (aspect 3 ) are probable hindrances to its use as a PSM.

\subsubsection{Hierarchical Process Modelling}

HPM was developed at the University of Bristol based on the idea of combining uncertain inference using Interval Probability Theory (IPT) with a strong process-based view of system description (Hall et al., 1998). It has been used in the Civil Engineering domain to support a process known as Evidential Discourse for ENgineering (EDEN) (Davis and Hall, 2003; Marashi, 2006, Marashi and Davis, 2006, Marashi, Davis and Hall, 2008) and more recently as an epistemic device (in the Checkland and Howell (2004) sense) to decide how to intervene in a messy problematical situation, in effect providing the systems modelling approach to implement a PSM (Davis et al., 2010).

HPM provides a conceptual schema for enacting a transformation, which can be thought of as its purpose, and agreeing this transformation forms part of the model building process. This declarative style enables inclusion of objects fulfilling an active role within a conceptual model of a system and provides a useful way of modelling across and between the social and technical realms. Eliciting hierarchical system structure proceeds from this top-level transformational process through repeated questioning of how? until there is no longer a process answer to these how? questions. Each of these processes is described in a gerund form (a subtle but distinct difference from the verb modelling used by Checkland in SSM). The gerund originates from Latin grammar, which can be understood as a word construct that means "(which is) to be carried out" using the active present (or continuous) form. Gerund forms have no subject, and the agent (performer) is not specified. Their use stimulates a degree of creativity in modelling where even physical entities can be considered as processes e.g. a 
chair becomes "supporting sitter" in gerund form. Answering how this process is to be achieved opens up options for achieving success, other than just a chair.

Having introduced the idea of the success or otherwise of a process a performance measure is assigned, which has been implemented in HPM by the use of interval numbers, (Hall et al., 1998) which can be represented by the use of the 'Italian Flag' notation (see later in Figure 2). Leaf processes can be scored using an Italian Flag scale that details what is known to be good about this process (green), what is known to be bad about this process (red) and what is uncertain or unknown (white). These scores are typically aggregated up the hierarchy using sufficiency and necessity conditions drawing upon a variation of the IPT described by Hall et al., 2008 called the Juniper algorithm (Marashi, 2006), which has been found to more suitable for modelling messy problems than the original IPT.

In all nine aspects of the GCD (Yearworth and White, 2014) use of HPM with the Italian Flag notation as a PSM would be considered as entirely valid, sharing as it does many similarities with SSM. This is a reasonable assertion so long as its functionalist roots are ignored. In particular, the use of software to support propagation of evidence is relegated to the supporting role as a device to check for model consistency (Yearworth, Lowe, Schien and Walworth, 2015) and documentation. In practice, group model building with HPM, including evidence expressed in Italian Flag notation, is perfectly feasible without software support, for example see the analysis contained within White, Burger and Yearworth (2015).

\subsubsection{Multi-methodology Approach}

The method - as described in the next section - involves the combination of the Italian Flag (interval number) scheme for ascribing evidence of process performance from HPM within an assessment structure developed from an adaptation of VSM. The method is thus properly considered as a product of a multi-methodology (Mingers, 2001; Mingers and Gill, 1997; Mingers and Brocklesby, 1997).

The combination of VSM and HPM methods appears to be novel as no reference to blending of VSM with HPM has been found in the literature. In fact only 12 of the 155 (or $8 \%$ ) mixed method papers reported by Munro and Mingers (2002) featured VSM - paired either with Soft Systems Methodology or Influence Diagrams. VSM does not feature in the more recent review of 30 mixed methods by Howick and Ackermann (2012) and HPM does not feature in either review.

As the ontological, epistemological and axiological assumptions (Mingers, 2003) that underpin VSM and HPM methods are different the possibility of paradigm incommensurability (Schultz and Hatch, 1996) needs to be considered. However, this is found not to be a concern in this instance as VSM and HPM have been used simultaneously in a parallel multi-methodology under an interpretive paradigm 
(Pollack, 2009). Consequently, there was no need for recourse to strategies for mitigating cultural and cognitive difficulties as reported by others (Kotiadis and Mingers, 2006).

In adopting being flexible and adaptable in response to stakeholder needs, combining and modifying parts of different methods, and in using processes of critical reflection (including jointly with participants), the authors identify the methodology as detailed below as aligning most closely with the 'pragmatic pluralism' tradition of multimethodology (Taket and White, 1996; Taket and White, 1998). This tradition has grown from its post-modern roots (Coercive-Plural box of SoSM) to be used in other settings where plurality in the nature of the client, use of specific methods, modes of representation and facilitation processes are manifest (Taket and White, 2000).

\section{$\underline{2.2 \text { Methodology }(\mathrm{M})}$}

The methodology involved the development, population and visualisation of a structured assessment. The key methodological consideration that drove the requirement for a consistent structure was the need to repeat this assessment over time in a longitudinal sense in order to identify trends. It was insufficient to merely highlight strengths and weaknesses in isolation.

\subsubsection{Developing an assessment structure}

The structure was developed through the application of an adapted VSM at two different levels to examine the Infrastructure Delivery System in the wider context of the Defence Enterprise. This adaptation was driven by the difficulty that stakeholders found in discriminating between Beer's S3 (control), S3* (audit) and S2 (coordination) because they regarded these functions as largely indistinguishable within the role of management. Given the short period of time available, and the opportunity to respond to stakeholder feedback (embracing the participative nature of the work in order to strengthen stakeholder buy-in), the authors elected not to attempt to disentangle this manifest undifferentiated amalgamation of functionality. Instead, these functional requirements were collapsed into a single layer to yield an adapted VSM focused on four key functions (with associated subfunctions):

1. Strategic Leadership (Beer's S5): Setting strategic direction; Setting strategic incentives; and Managing strategic performance and risk.

2. $\quad$ Strategy Formulation (Beer's S4): Capturing inputs and constraints; Setting strategy; and Monitoring strategy implementation.

3. Operational Management (Beer's S3, S3* and S2): Setting management direction; Managing performance and risk; Assuring delivery coherence; and Assuring and auditing performance. 
4. Operational Delivery (Beer's S1): Understanding user requirements; Understanding supplier capabilities; Delivering projects and services; and Managing delivery performance and risk.

In responding to stakeholders' needs in accommodating cognitive accessibility to the modelling approach the adaptation / creativity feature of the PSM GCD (aspect 3) has been embraced but at the cost of weakening or even breaking the need to avoid conceptual limitations (aspect 9). This is an important balance to strike and is worthy of further research. However, in this case the immediate need was for modelling support at a conceptual level for problem structuring (very much in the soft systems paradigm identified in Table 3.1 of Checkland and Holwell (2004)). Therefore it is argued that the methodology has retained adequate theoretical grounding in the VSM to not risk damaging the credibility of the overall approach as a PSM (Ackermann, Franco, Rouwette and White, 2014) - no aspect of the VSM has been discarded (although it is acknowledged that there is a risk that the interplay between Beer's S2, S3 and S3* may have been considered less explicitly than in a traditional VSM approach). This issue is returned to in the discussion section.

Figure 1 illustrates how the adapted VSM was applied to the Infrastructure Delivery System (S) in the context of the Defence Enterprise (E). The Infrastructure Delivery System is an element of the function E4 but, to be viable, needs to itself address all four elements of the model (represented as functions S1 -S4), as well as relationships with both the external environment and with the remainder of Defence Enterprise Operational Delivery.

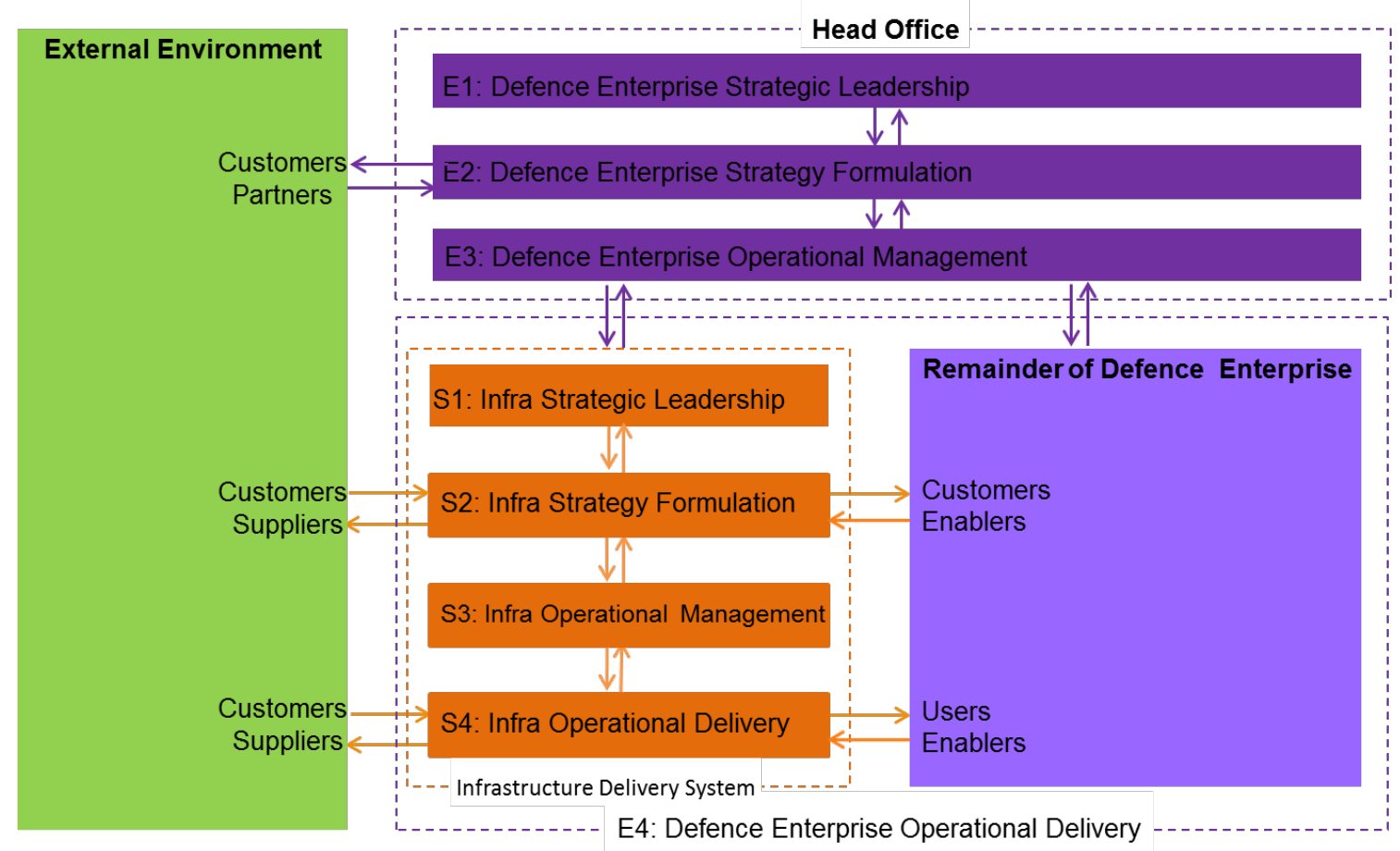

Figure 1 - Assessing the Infrastructure Delivery System in the context of the Defence Enterprise 


\subsubsection{Populating the assessment structure}

The assessments were undertaken via two workshops, one focussing on 'Defence Enterprise Operational Management' (function E3) as it pertained to infrastructure delivery and the other focussing on 'Infrastructure Delivery System' (functions S1-S4). For each function and associated sub-functions both the performance and the associated interfaces (vertically between the functions and horizontally with the external environment and remainder of Defence Enterprise) were examined.

The workshop participants were those stakeholders identified as having responsibility for and/or experience of key elements within functions E3 and S1-S4, as well as those representing the Infrastructure customer base (principally the Armed Forces). It was important to ensure that the participants were both expert and representative of all sides (i.e. DIO, Governors and Customers). The role of the consultants was then to act as facilitators to ensure that a balanced assessment was arrived at and that it was supported by objective evidence wherever possible. The open questions that were used to guide the facilitation of the second workshop are detailed in Appendix A.

Whilst the aim of each workshop was to identify strengths, weaknesses and uncertainties associated with each element of the framework under consideration, before these could be identified it was necessary to establish who was responsible for performing these functions, because the framework is based on functional performance and not organisational form. This was achieved for each element via a simple RACI exercise where participants proposed, debated and reached consensus on who was Responsible, Accountable, Consulted and Informed.

In the next step, the workshop participants collectively identified the strengths, unknowns or weaknesses from their personal perspectives. These contributions were captured and displayed by facilitators before being discussed as a group to build shared understanding (without any attempt to drive consensus). The participants were then asked to individually score the relative weight of the strengths (green), unknowns (white) and weaknesses (red) on a 10 point scale and to provide explanatory comments on individual assessment sheets. This scoring was not based on the number of strengths, weaknesses or unknowns, but rather on their cumulative impact on functional performance.

\section{$\underline{2.2 .3 \text { Visualising Results }}$}

The scores and comments for each function and sub-function were subsequently collated and an 'Italian Flag' was drawn using the median values calculated from the individual scores and normalised to fit on a scale from one to ten. It was interesting to note that for all the debate there was really very little variation about these median values. Figure 2 shows how the scores for the 'Infrastructure Delivery System' function were visualised as a HPM (but note that this visualisation is not representative of the actual results owing to their sensitivity). 


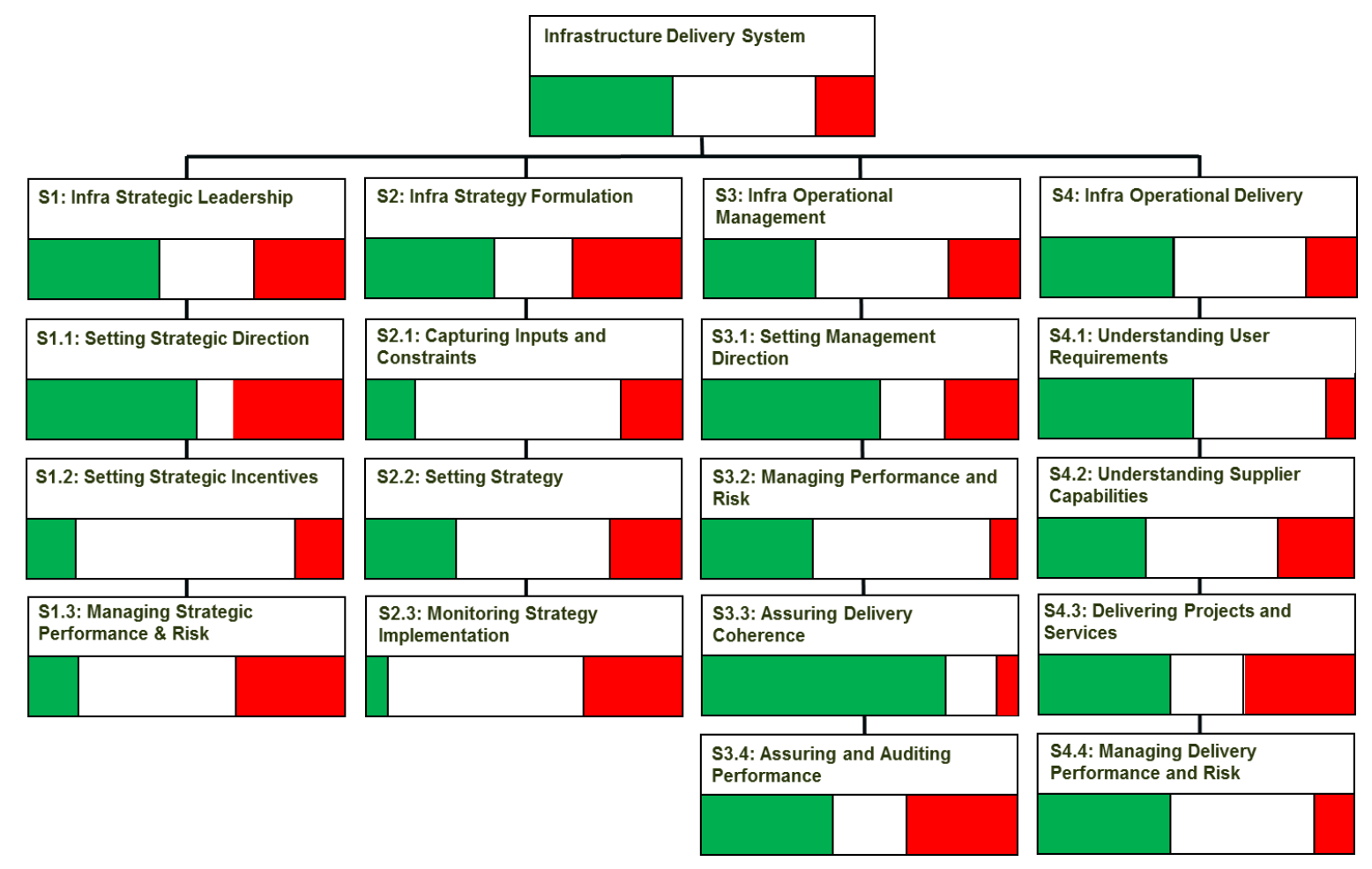

Figure 2 - Hierarchical Process Model for Infrastructure Delivery System (illustrative purposes only)

It should be noted that this is not how HPMs are traditionally constructed (see Blockley and Godfrey, 2000; Davis and Hall, 2003). Firstly, the aggregation between sub-function and function level was not carried out through the use of necessity and sufficiency conditions (Hall et al., 1998), rather the aggregation was carried out by the workshop participants. This offers an opportunity for further learning in that it is possible to check for consistency between supplied rationale and necessity and sufficiency values. Secondly, the model has been structured through the adapted use of VSM before being populated. Traditionally, a HPM is derived through group model building where the model is both constructed and populated using expert judgment. The adaptation was however influenced by the stakeholders as described above but also through one-to-one interviews before the workshops. These interviews proved critical in providing an opportunity to introduce the model structure and to fine tune at the sub-function level to ensure that it would provide an appropriate structure for use in the workshops.

This second point has precedent in the use of preliminary models in the planning phases that proceed system dynamics workshops (Vennix, 1996; Figure 4.1). This preliminary modelling, supported by conducting interviews and/or ingesting documentation, has been established as a key phase in the Group Model Building (GMB) method (Andersen and Richardson ,1997; Andersen et al., 2007). That is not to say that workshops must be proceeded by such preliminary activity, more that this activity can be a powerful catalyst for discussion with key managers in order to clarify objectives, scope and approach in advance and so significantly de-risk the event itself. 


\subsubsection{Critiquing the method as a PSM}

The GCD for PSM put forward by Yearworth and White (2014) has already been used to critique the VSM aspect of the work in $\$ 2.1 .2$ above and its adaptation in $\$ 2.2 .1$, and to validate the use of HPM as a PSM in $\S 2.1 .3$. It is now used to critique the hybrid VSM/HPM method as a whole that is put forward in this paper with a determination of the truth of each element. This comparison suggests that this approach can be considered to be a PSM.

(1) Improvement activity - TRUE; The VSM/HPM method was adopted in response to the need to take action in a problematic situation.

(2) Systemic approach - PARTIALLY TRUE; Both the VSM and HPM were developed with strong foundations in cybernetics, and systems thinking and provide an appropriate systems modelling approach to support stakeholders expressing their views. However, the cognitive accessibility of the VSM has been questioned by stakeholders leading to its adaptation. Perhaps the only limitation in the implementation has been any formal approach to boundary critique.

(3) Adaptation / Creativity - TRUE; Existing methods have been adapted and creativity demonstrated in that this is the (apparently) first hybridisation of these techniques leading to a determination that this aspect of the GCD has been confirmed. However, the VSM was conceived as a model that must be used in its entirety for it to be meaningful. This sets a dilemma for this aspect of the GCD rather than for the users of this adapted form.

(4) Methodological lessons - TRUE; The use of the FMA framework from Checkland and Holwell (1998) has been used to underpin the design of this action research. The findings presented in this paper represent reflections on the use of the method and lessons learned, including via the use of a formal evaluation approach.

(5) Worldviews - PARTIALLY TRUE; The method only acknowledged and worked with different worldviews in as far as reflecting the differing degrees of belief in the performance of the functions in the model. The model structure however was fixed and thus could not reflect differing views about system structure (although it was developed and adapted in response to stakeholder perspectives elicited during group and individual consultations). In this regard the method could have constrained representational thought.

(6) Messiness - TRUE; The problem context was recognised as messy by the stakeholders. The problem structuring reported in this paper was an essential first step in deciding how to intervene. In particular this work highlighted that many of the issues lay outside the organisational boundary of the DIO.

(7) Interactive / Iterative / Therapeutic - TRUE; Dstl was brought in as experts in OR and systems thinking but not as experts in the domain of the stakeholders. Dstl acted as facilitators in a number of workshops with the stakeholders. 
(8) Subjectivity - TRUE; This was recognised by the facilitators, stakeholders and sponsor. Whilst efforts were made to identify evidence to support stakeholder judgments, this largely proved impossible. The approach instead relied upon balancing judgments across the customer-supplier-stakeholder boundaries to minimise biases, and upon ensuring that the right personnel were invited to participate to ensure access to subject matter expertise.

(9) Limits - UNKNOWN; The evaluation of the method that has been carried out has not examined this aspect of the GCD. Whilst it appears that the method developed was adequate for purpose and avoided conceptual limitations, this has not been proven and so this aspect of the GCD is assessed to be unknown.

\section{Results}

The resulting model identified key strengths, weaknesses and uncertainties for 'Head Office Management and Governance of the Defence Enterprise' (covering E3) and 'Infrastructure Delivery System' (covering S1-4). These results are sensitive and so are not detailed here (recall that Figure 2 is illustrative only of how the S1-4 results were visualised and not of the results themselves).

However, the actions identified to either improve performance (and so minimize red assessments) or to reduce uncertainty (minimize white assessments) can be disclosed. At the end of each workshop participants were asked to collectively identify their top priorities for action. Eight actions were identified based upon five key weaknesses and three key areas of uncertainty (it is interesting to note how the actions identified to address weakness are more specific than those identified to address uncertainty):

a. Weakness 1: Manage Infrastructure Delivery System as a whole

b. Weakness 2: Establish incentives for 'Defence first' behaviours

c. Weakness 3: Develop Intelligent Customer status (Head Office and FLCs)

d. Weakness 4: Accelerate roll-out of management information systems

e. Weakness 5: Link Infrastructure delivery to Defence objectives

f. Unknown 1: Define scope of Infrastructure Delivery System

g. Unknown 2: Test, formalise and communicate internal interfaces

h. Unknown 3: Test, formalise and communicate external interfaces

These recommended actions were readily accepted by the senior customer (who was not party to any of the workshop discussions) and used to define the forward work plan for the Defence Infrastructure Governance Authority - the body established to govern the operation of DIO. Stakeholder feedback 
was very complementary with regard to impact. For example: "The Dstl work made a real difference in the success of the Defence Infrastructure System Programme definition stage. In particular it enabled us to arrive at an agreed maturity model much more quickly than would otherwise have been the case as many of the key stakeholders had already been through the thought process that led them to understand the functions within the system. In addition, your work with them around the Italian Flag assessment resulted in a common understanding of system weaknesses. This enabled us to reach a rapid and robust consensus as to the current state of the Infrastructure System and priorities for corrective action"

\section{Discussion}

Whilst it is evident that the research was successful, a formal evaluation approach was implemented to expand on the informal, unstructured feedback received from the customer and so provide a firm foundation for methodological learning - one of the nine aspects identified in the GCD and a key element of action research.

This formal evaluation approach was based upon the framework put forward by Midgley, Cavana, Brocklesby, Foote, Wood and Ahuriri-Driscoll (2013). A qualitative questionnaire was developed that covered the four areas outlined by Midgley and his co-workers - namely Purpose, Context, Method and Outcomes (see Appendix B). The questionnaire was distributed and completed by both study stakeholders and the research team themselves

This section discusses four key methodological learning insights that emerged from this evaluation activity and that appear readily transferrable to other areas. Areas for further research are also highlighted.

\subsection{The VSM provided a sound basis for structuring the Method}

The first key consideration in the design of the Method was the need to comprehensively cover the functionality required of the system in focus. The VSM provided this comprehensiveness and readily brought credibility with stakeholders given its sound theoretical basing in cybernetics and widespread use to good effect as detailed in the literature.

The second key consideration was the need for the model to act as a boundary object (Franco, 2013) to engender constructive debate between stakeholders. The focus on organisational function and not organisational form was found to be very helpful in this regard. As Beer himself observed: "models of management are useful for little more than apportioning blame” (Beer, 1984). This focus on function over form also has resonance with the ideas of Rummler and Brache (1990, pp 8-9) who 
advocate taking a systems or horizontal view of an organisation in order to focus on how the organisation manages the whitespace or 'critical interfaces' between elements on the organisational chart in order to deliver value, as opposed to a traditional or vertical view that focuses on the management of these individual elements.

The third key consideration was the need to enable the examination of the system in the context of the wider enterprise and so ensure appropriate scope. The recursive nature of VSM was therefore critical. Recursion affords the examination of the system-in-focus (level 1) in the context of both the level above (level 0) and the level below (level 2) and so providing "an integrated understanding of the situation" (Yolles, 1999).

\subsection{The HPM representation proved to be very powerful in the messy problem Context}

The Italian Flag visualisation was designed as a means to "facilitate discussion between players about the reasons for their assessments and to iron out those differences to gain understanding" (Blockley and Godfrey, 2000). However, in this instance, there was generally good agreement amongst the stakeholders (perhaps because the discussion preceded the scoring) and there was no need to revisit the scoring to reach accommodation. The visualisation was new to every stakeholder but the key concepts were quickly picked up and the scheme proved effective as a means to summarise stakeholder assessments. In particular the stakeholders appreciated that the visualisation was able to simultaneously convey their judgments with respect to the relative balance of what was good, bad and unknown about a process. The most commonly used alternative in the MOD context is traffic light assessments (where the use of red, amber or green represents the net balance of performance) sometimes paired with a code to indicate the quality of the evidence behind such an assessment (e.g. A for objective evidence supplied through to D for subjective judgment only).

The results were presented to the senior sponsor in overview as a HPM because this seemed to strike a good balance between conveying the methodological rigour and summarising the key findings in an accessible manner. The main evidence points for each function were then detailed in a table whose row heights were sized using the associated flag. This proved to be a useful aid for synthesis as the height of the row provided a guide as to how much evidence should be provided.

The use of the HPM method affords the potential to automatically aggregate Italian Flag scores up the tree structure (Marashi et al., 2008). This affordance has not yet been exploited because, whilst the it could be viewed as providing assistance to stakeholders, automatic aggregation was assessed to be incommensurate with the participative nature of the methodology and there was a concern that it could alienate the participants from 'their' results and that an associated reduction in ownership would put implementation at risk. Whilst software is unnecessary for the implementation of this hybrid VSM/HPM method it could support checking for model consistency (Yearworth et al., 2015). 
However, the question of structural consistency of a systems model with belief about its performance hinges on a 'hidden' feature of the way in which evidence is combined, in this case the necessity, sufficiency and independence of sub-processes to their superior process (Marashi et al., 2008; Hall et al., 1998). Whilst sufficiency conditions can be exploited to make categorical statements about how a failing sub-process could lead to failure of the whole system, again this is the functionalist thinking behind HPM's original design creeping into this use as a PSM. For now, these questions remain open and an area of further work.

For completeness, and in order to provide a reference for how HPM has been used by itself as a PSM, the application of HPM as a PSM is summarised in Appendix C.

\subsection{Adaptation and mixing proved critical to successful Outcome:}

The VSM has been critiqued for being inaccessible - with highly technical visual representations and difficult language creating substantial cognitive barriers (see Checkland 1980; Ulrich, 1981; Jackson 1988). This was confirmed in this Context and drove significant adaptations (e.g. simplification of the framework into four layers, renaming of layers and sub-functions). The adapted VSM was then used to develop a framework, which was populated by subject matter experts in the style of a HPM but without recourse to necessity and sufficiency conditions to handle aggregation. This adaptation and mixing means that it is unclear how best to refer to the resulting method which goes some way to explaining the title of this paper.

Creative adaptation is recognised to be an aspect of PSM approaches (Yearworth and White, 2014) and the method reported here is clearly an example of such. However, the adaptation of the VSM and HPM is potentially troubling from the perspective of reducing their value as systems models. The authors are sensitive to Jackson's rather trenchant critique in Creative Holism of the use of another systems modelling approach with functionalist roots - qualitative system dynamics - as an "under theorised soft systems methodology" (Jackson, 2003). But this is to fall into the trap of constraining the use of these methods to their functionalist roots. This use of the modelling approaches of HPM and the VSM has been essentially interpretivist, aligned with the repurposing of them in support of problem structuring. This does beg the question of how far it would be possible to go with modifying a model such as VSM before its value is rendered meaningless. Without further research it is impossible to answer the question.

The authors have instead focused on the adequacy of the methodology and the question of whether the knowledge generated through this process is valid - i.e. has the knowledge generated by the process been transformative? Ultimately, this is not really a question of formal evaluation of Method according to approaches such as described by Midgley et al. (2013), Ormerod (2013), White (2006) or Pawson and Tilley (1997) or whether the approach developed confirmed to a strict definition of a 
PSM (Yearworth and White, 2014). The question can only be answered by returning to the Checkland and Holwell (1998) framework used in the research design and in particular what has been learned about the problem situation, and thus the ability of the Methodology (M) to impact on the area of concern (A). The knowledge generated was transformative in this sense - recall the observations from one of the key stakeholders in $\S 3$.

\subsection{Preparation and facilitation were critical to meeting the Purpose}

Meeting the Purpose hinged on the execution of two facilitated modelling workshops because of the need to surface, discuss and balance multiple worldviews. In such workshops OR consultants are required to "deploy both facilitation and modelling skills" (Franco and Montibeller, 2010). The variation in this case study is that the modelling skills were also deployed in advance of the workshops by the consultants firstly acting in an 'expert' mode to develop the assessment structure and then in 'facilitator' mode to refine it in conversation with individual stakeholders.

These preparatory one-on-one interviews served two key purposes. Firstly, it provided an opportunity to introduce and discuss the aims and method to be used at the workshop, which saved time on the day and ensured that participants came to the workshop fully prepared. Secondly, it provided an opportunity to identify issues and adjust the workshop plan accordingly, which reduced the risk of the workshop not meeting its aims. Whilst this might be unusual it was appreciated by workshop participants because it allowed them to spend more of their limited time on model population and discussion, and less time on model building.

The learning point here then is that when it is difficult to gather the stakeholders together for any length of time - and this seems increasingly to be the case - individual stakeholder engagement in advance should be conducted. Whilst there is precedent for this type of engagement - as discussed in $\$ 2.2 .4$ - there is a concern that such pre-work could constrain and/or bias the problem structuring activity itself. Future research could investigate the extent to which this type of engagement affects achievement of Purpose and/or delivery of Outcomes.

\section{Conclusions}

This paper has described how the authors integrated VSM and HPM in a multi-methodology for successful use as a PSM and has identified a number of methodological learning points including through the use of a formal evaluation approach. In doing so the authors believe that this paper makes a contribution to five out of the eight challenges recently identified for problem structuring research and practice (Ackermann et al., 2014). 
Developing effective support for multi-organisational collaborative working - First and foremost the application of this method has provided a basis for the co-development of interventions in a complex multi-organisational context. The method provided a comprehensive structure that proved helpful in ensuring both appropriate coverage and appropriate focus on key issues. The RACI exercise proved critical to raising shared understanding of who was responsible for what in the new ways of working. The resulting model proved to be very effective as a boundary object that enabled stakeholders to engage in constructive debate on what intervention action to take.

Building on prior problem structuring research - Second, the method builds upon the foundations of existing methods and the methodological lessons identified through their use to develop a new method. Specifically it drew upon the development of VSM and HPM methods by researchers and their application by a range of practitioners in a variety of contexts. This prior work provided the bulk of the framework of ideas for this action research effort and the methodological lessons these authors identified greatly influenced the adaptation and mixing of these methods to yield a new method. Whilst developed to address a specific issue within MOD, this new method appears to offer opportunities and be readily transferrable to other multi-organisational contexts.

Developing effective procedures for mixing methods - Third, this research has mixed VSM and HPM methods for use as a PSM under the soft paradigm (apparently for the first time). This would have been very difficult if VSM and HPM had been used traditionally and consequently adaptation of both proved to be critical to suit the specific context. Whilst the VSM provided a credible a priori structure for model development, stakeholders found some aspects confusing and this drove the adaptation to a four-layer model. Further, the aggregation within the HPM structure using necessity and sufficiency conditions was eschewed in favour of more participant-focused approach in order to ensure that stakeholders retained ownership of the findings. The resulting hybrid method is found to afford more than the sum of its parts.

Maintaining high quality standards in problem structuring work - Fourth, this work has shown how the recently-proposed GCD for problem structuring can be used to guide development and so maintain high standards for problem structuring work. This paper has detailed how the GCD has been used to critique and reflect on both the constituent parts (i.e. VSM and HPM) but also the hybrid method as a whole. But more than an aid for rearward critique, the GCD has provided a robust basis for the forward design by providing guidance for what the essence of a PSM should be.

Ensuring the desired level of neutrality in modelling process and content - Fifth, this work has shown how practitioners can combine their methodological expertise with their facilitation skills in order to support the development of effective interventions whilst maintaining neutrality on the findings. The method provides a means by which to manage the Process (P) and Content (C) whilst leaving the Substance (S) to the stakeholders (Eden, 1990; Huxham and Cropper, 1994). The method is 
'therapeutic' in that it leverages the domain expertise of stakeholders elicited through facilitated workshops; but it also leverages the methodological expertise of the researchers in the development of the assessment structure and in the design of the assessment process to ensure that the assessment is both comprehensive and appropriately focused.

\section{References}

Ackoff R L (1977). Optimization + objectivity = opt out. European Journal of Operational Research 1(1): $1-7$.

Ackoff R (1979). The future of operational research is past. Journal of Operational Research Society 30: $93-104$.

Ackermann F (2012). Problem structuring methods 'in the Dock': Arguing the case for Soft OR. European Journal of Operational Research 219(3): 652-658.

Ackermann F, Franco L A, Gallup B and Parent M (2005). Group support systems for multiorganizational collaboration: reflections on process and content. Group Decision and Negotiation 14(4): 307-331.

Ackermann F, Franco L A, Rouwette E and White L (2014). Problem structuring research and practice for the next decade looking back to go forward. EURO Journal on Decision Processes 2(3-4): 164-72.

Andersen D, Vennix J, Richardson G and Rouwette E (2007). Group model building: problem structuring policy simulation and decision support. Journal of the Operational Research Society 58(5): 691-694.

Andersen D F and Richardson G P (1997). Scripts for group model building. System Dynamics Review 13(2): 107-129.

Argyris C, Putnam R and Smith D M (1985). Action science : concepts methods and skills for research and intervention. Jossey-Bass: San Francisco.

Beer S (1972). Brain of the Firm. John Wiley: Chichester.

Beer S (1979). Heart of the Enterprise. John Wiley: Chichester.

Beer S (1985). Diagnosing the System for Organisations. John Wiley: Chichester.

Beer S (1984). The Viable System Model: Its Provenance Development Methodology and Pathology. Journal of the Operational Research Society 35(1): 7-25.

Blockley D and Godfrey P (2000). Doing it differently: systems for rethinking construction. Thomas Telford: London.

Brocklesby J and Cummings S (1996). Designing a Viable Organizational Structure. Long Range Planning 29(1): 49-57.

Brocklesby J (2012). Using the Viable Systems Model to examine multi-agency arrangements for combatting transnational organised crime. Journal of the Operational Research Society 63(3): $418-430$.

Brydon-Miller M, Greenwood D and Maguire P (2003). Why Action Research? Action Research 1(1): 9-28.

Checkland P (1980). Are organisations machines? Futures 12(5): 421-424

Checkland P (1981). Systems Thinking Systems Practice. John Wiley: Chichester. 
Checkland P and Holwell S (1998). Action research: Its nature and validity. Systemic Practice and Action Research 11: 9-21.

Checkland P and Holwell S (2004). "Classic" OR and "soft" OR - an asymmetric complementarity In M Pidd (Ed) Systems Modelling: Theory and Practice. John Wiley: Chichester.

Davis J P and Hall J W (2003).A software-supported process for assembling evidence and handling uncertainty in decision-making. Decision Support Systems 35(3): 415-33.

Davis J, Macdonald A and White L (2010). Problem-structuring methods and project management: an example of stakeholder involvement using Hierarchical Process Modelling methodology. Journal of the Operational Research Society 61(6): 893-904.

Eden C L (1990). Strategic thinking with computers. Long Range Planning 23(6): 35-43.

Eden C and Ackermann F (2006). Where next for problem structuring methods. Journal of the Operational Research Society 57(7): 766-768.

Eden C and Ackermann F (2013). 'Joined-Up' policy-making: group decision and negotiation practice. Group Decision and Negotiation 23(6): 1385-1401.

Espejo R, Bowling D and Hoverstadt P (1999). The viable system model and the Viplan software. Kybernetes 28(6/7): 661-678.

Espinosa A, Reficco E, Martínez A and Guzmán D (2014). A Methodology for Supporting Strategy Implementation Based on the VSM: A Case Study in a Latin-American Multi-National. European Journal of Operational Research 240: 202-212.

Espinosa A and Walker J (2013). Complexity Management in Practice: A Viable System Model Intervention in an Irish Eco-Community. European Journal of Operational Research 225: 118129.

Flood R and Jackson M (1991). Creative Problem Solving. John Wiley: Chichester.

Franco L A (2006). Problem structuring methods as intervention tools: reflections from their use with multi-organizational teams. Omega 37(1): 193-203.

Franco L A (2007). Facilitating Collaboration with Problem Structuring Methods: A Case Study of an Inter-Organisational Construction Partnership. Group Decision and Negotiation 17: 267-286.

Franco L A (2013). Rethinking soft OR interventions: models as boundary objects. European Journal Operational Research 231(3):720-733.

Franco L A and Lord E (2011). Understanding multi-methodology: Evaluating the perceived impact of mixing methods for group budgetary decisions. Omega-International Journal of Management Science 39(3): 362-372.

Franco L A and Montibeller G (2010). Facilitated modelling in operational research. European Journal of Operational Research 205: 489-500.

Friend J K and Hickling A (1987). Planning under Pressure: The Strategic Choice Approach. Pergamon: Oxford.

Hall J W, Blockley D I and Davis J P (1998). Uncertain inference using interval probability theory. International Journal of Approximate Reasoning 19(3-4): 247-264.

Hildbrand S and Bodhanya S (2014). Application of the viable system model in a complex sugarcane supply chain. British Food Journal 116(12): 2048-2068.

Hildbrand S and Bodhanya S (2015). Guidance on applying the viable system model. Kybernetes 44(2): 186-201.

Hindle G A and Franco L A (2009). Combining problem structuring methods to conduct applied research: a mixed methods approach to studying fitness-to-drive in the UK. Journal of the Operational Research Society 60(12): 1637-1648. 
Howick S and Ackermann F (2011). Mixing OR methods in practice Past present and future directions. European Journal of Operational Research 215: 503-511.

Huxham C and Cropper S (1994). From many to one and back: an exploration of the components of facilitation. Omega 22(1): 1-11.

Jackson M C (1988). An appreciation of Stafford Beer's viable system viewpoint on management practice. Journal of Management Studies 25: 557-573.

Jackson M C (2001). Critical systems thinking and practice. European Journal of Operational Research 128: 233-244.

Jackson M C (2003). Systems Thinking: Creative Holism for Managers. John Wiley: Chichester.

Kotiadis K and Mingers J (2006). Combining PSMs with hard OR methods: the philosophical and practical challenges. Journal of the Operational Research Society 57(7): 856-867.

Levene L (2011). Defence Reform: An independent report into the structure and management of the Ministry of Defence. Ministry of Defence.

Marashi S E (2006). Managing Discourse and Uncertainty for Decision-making in Civil and Infrastructure Engineering Systems (PhD). University of Bristol.

Marashi E and Davis J P (2006). An argumentation-based method for managing complex issues in design of infrastructural systems. Reliability Engineering and System Safety 91(12): 1535-1545.

Marashi SE Davis J P and Hall J W (2008). Combination methods and conflict handling in evidential theories. International Journal of Uncertainty Fuzziness and Knowledge-Based Systems 16(3): $337-369$.

Midgley G Cavana R Y, Brocklesby J, Foote J L, Wood D R R and Ahuriri-Driscoll A (2013). Towards a new framework for evaluating systemic problem structuring methods. European Journal of Operational Research 229(1): 143-154

Mingers J (2001). Multimethodology - Mixing and Matching Methods In J Rosenhead and J Mingers (Eds) Rational Analysis for Problematic World Revisited. John Wiley: Chichester.

Mingers J (2003). A classification of the philosophical assumptions of management science methods. Journal of the Operational Research Society 54(6): 559-570.

Mingers J (2011). Soft OR comes of age-but not everywhere! Omega-International Journal of Management Science 39(6): 729-741.

Mingers J and Brocklesby J (1997). Multimethodology: Towards a framework for mixing methodologies. Omega-International Journal of Management Science 25(5): 489-509.

Mingers J and Gill A (1997). Multimethodology : the theory and practice of integrating management science methodologies. John Wiley: Chichester.

Mingers J \& Rosenhead J (2004). Problem structuring methods in action. European Journal of Operational Research 152(3): 530-554.

Mingers J and White L (2010). A review of the recent contribution of systems thinking to operational research and management science. European Journal of Operational Research 207 1147-1161.

Munro I Mingers J (2002). The use of multimethodology in practice - Results of a survey of practitioners. Journal of the Operational Research Society 53: 369-378.

Ormerod R (2013). The mangle of OR practice: towards more informative case studies of 'technical' projects. Journal of the Operational Research Society. doi: doi:101057/jors201378.

Pawson R and Tilley N (1997). Realistic Evaluation. Sage: London.

Pollack J (2009). Multimethodology in series and parallel: strategic planning using hard and soft OR. Journal of the Operational Research Society 60(2): 156-167. 
Preece G, Shaw D and Hayashi H (2013). Using the Viable System Model (VSM) to structure information processing complexity in disaster response. European Journal of Operational Research 5: 67-78.

Reynolds M and Holwell S Eds (2010). Systems Approaches to Managing Change: A Practical Guide. Springer: London.

Rittel H and Webber M (1973). Dilemmas in general theory of planning. Policy Science 4: 155-69.

Rosenhead J (1996). What's the Problem? An Introduction to Problem Structuring Methods. Interfaces 26(6): 117-131.

Rosenhead J (2006). Past present and future of problem structuring methods. Journal of the Operational Research Society 57(7): 759-765.

Rummler G A and Brache A P (1990). Improving performance: How to Manage the White Space on the Organisation Chart. Jossey-Bass: San Francisco.

Schultz M and Hatch M J (1996). Living with multiple paradigms: The case of paradigm interplay in organizational culture studies. Academy of Management Review 21(2): 529-557.

Schon D (1987). Educating the Reflective Practitioner: Toward a New Design for Teaching and Learning in the Professions. Jossey-Bass: San Francisco.

Taket A and White L (1996). Pragmatic Pluralism - An Explication. Systems Practice 9(6): 571-586.

Taket A and White L (1998). Experience in the practice of one tradition of multimethodology. Systems Practice and Action Research 11(2): 153-167.

Taket A and White L (2000). Partnership and participation: decision-making in the multi-agency setting. Wiley: Chichester

Tavella E and Papadopoulos T (2015). Expert and novice facilitated modelling: A case of a Viable System Model workshop in a local food network. Journal of the Operational Research Society 66(2): $247-264$.

Ulrich W (1981). A critique of pure cybernetic reason: the Chilean experience with cybernetics. Journal of Applied Systems Analysis 8: 33-59.

Vennix J (1996). Group Model Building: Facilitating Team Learning Using System Dynamics. John Wiley: Chichester.

White L (2006). Evaluating problem-structuring methods: developing an approach to show the value and effectiveness of PSMs. Journal of the Operational Research Society 57(7): 842-855.

White L (2009). Understanding problem structuring methods interventions. European Journal of Operational Research 199(3): 823-833.

White L, Burger K and Yearworth M (2015). Understanding behaviour in problem structuring methods interventions with activity theory. European Journal of Operational Research. doi: 101016/jejor201507044

Yearworth M and White L (2014). The Non-Codified Use of Problem Structuring Methods and the Need for a Generic Constitutive Definition. European Journal of Operational Research 237: 932 945.

Yearworth M, Lowe D A J, Schien D and Walworth T (2015). From deciding to acting: hierarchical process modelling for problem structuring Paper presented at the Calculating and Communicating Uncertainty (CCU2015) Conference London UK.

Yolles M (1999). Management Systems. Financial Times Ltd: London. 


\section{Appendix A - Guiding Questions}

This appendix details the questions used guide the assessment in S1-S4 sub-function areas.

\begin{tabular}{|c|}
\hline S1: Infrastructure Strategic Leadership \\
\hline S1.1 Setting Strategic Direction \\
\hline How is Strategic Leadership for the Infrastructure Delivery System undertaken? \\
\hline Is Strategic Leadership direction focussed on achieving strategic benefit? \\
\hline How are strategic benefits and risks identified? \\
\hline Is a clear scope, vision and purpose set for the Infrastructure Delivery System? \\
\hline How is strategic direction communicated? \\
\hline S1.2 Setting Strategic Incentives \\
\hline How are incentives set on the Infrastructure Delivery System? \\
\hline What mechanisms are used? \\
\hline Do they encourage positive behaviours and drive efficiencies? \\
\hline Is incentivisation effective? \\
\hline S1.3 Managing Strategic Performance and Risk \\
\hline How are strategic benefits and risks tracked? \\
\hline How are strategic benefits and risks managed? \\
\hline How is it linked to strategic decision making? \\
\hline Does the Infrastructure Strategic Leadership own or have access to appropriate levers to enable necessary action? \\
\hline S2: Infrastructure Strategy Formulation \\
\hline S2.1 Capturing Requirements \\
\hline $\begin{array}{l}\text { How does the Infrastructure Delivery System develop an understanding of the external environment at a strategic } \\
\text { level, including identification of key strategic stakeholders? }\end{array}$ \\
\hline Are there clear and stable mechanisms in place to interface with and influence key strategic stakeholders? \\
\hline $\begin{array}{l}\text { Is there a clear mechanism for strategic 'Customer' requirements to be communicated into the Infrastructure } \\
\text { Delivery System? }\end{array}$ \\
\hline S2.2 Prioritising Requirements \\
\hline $\begin{array}{l}\text { How do 'Customers' articulate and prioritise those strategic requirements against which they wish the } \\
\text { Infrastructure Delivery System to deliver? }\end{array}$ \\
\hline $\begin{array}{l}\text { How does the Infrastructure Delivery System prioritise across all strategic customer requirements within } \\
\text { constraints? }\end{array}$ \\
\hline S2.3 Setting Strategy \\
\hline How is Infrastructure Strategy set? \\
\hline Are clear and measurable success factors set? Are they linked to Infrastructure strategic benefits? \\
\hline Is strategy coherent with Infrastructure strategic benefits and risks? What coherence mechanisms are in place? \\
\hline $\begin{array}{l}\text { Is strategy coherent with itself? With strategic Customer requirements? Long-term vs short-term? National vs } \\
\text { regional? Coherence mechanisms? }\end{array}$ \\
\hline $\begin{array}{l}\text { Is strategy comprehensive? } \\
\text { Does it address delivery, people, capability, enablers? }\end{array}$ \\
\hline S2.4 Monitoring Strategy Implementation \\
\hline $\begin{array}{l}\text { How is the implementation of Infrastructure Delivery System strategy tracked? Against Infrastructure and Defence } \\
\text { strategic success factors? }\end{array}$ \\
\hline S3: Infrastructure Operational Management \\
\hline
\end{tabular}




\section{S3.1 Setting Management Direction}

How is management direction set?

Is management direction compliant with local and wider strategic direction? Is it coherent across the Infrastructure Delivery System?

Are clear and measurable success factors set? Are they linked to 'Defence Strategy', MOD Centre and

Infrastructure success factors?

How are resources balanced across and allocated to Infrastructure Op Delivery?

How does Infrastructure Operational Management incentivise Infrastructure Op Delivery to drive positive

behaviours and efficiency?

\section{S3.2 Managing Performance and Risk}

How is Infrastructure Operational Delivery performance tracked and managed?

How is risk assessed and managed?

Does this include against strategic Infrastructure and 'Defence Strategy' success factors?

Is autonomy optimised for Infrastructure Operational Delivery?

What mechanisms exist for decision-making outwith delegations?

\section{S3.3 Assuring Delivery Coherence}

What mechanisms exist to ensure coherent delivery across the Infrastructure Operational Delivery?

Is there clarity of purpose for all elements of Infrastructure Operational Delivery?

Are the interfaces between each element of Infrastructure Operational Delivery clearly articulated and understood?

\section{S3.4 Assuring and Auditing Performance}

What mechanisms exist to assure and audit the performance of Infrastructure Operational Delivery elements? Are these mechanisms comprehensive? Are they effective?

Are audit and assurance activities prioritised against Infrastructure and Defence strategic benefit/risk?

\section{S4: Infrastructure Operational Delivery}

\section{S4.1 Understanding User Requirements}

Does each delivery element (Programme, Project, Service) understand the external environment at a delivery level, including identification of all primary Users?

How does each delivery element manage User relationships?

What mechanisms are used to build relationships, and interface and engage with Users?

How do delivery elements incentivise and influence Users?

What mechanisms are used to capture and respond to User requirements?

Are clear and stable relationships in place for each primary User?

\section{S4.2 Understanding Supplier Capabilities}

Does each delivery element (Programme, Project, Service) understand the external environment at a delivery level, including identification and understanding of current and potential suppliers?

How does each delivery element manage supplier relationships?

What mechanisms are used to build relationships, and interface and engage with current and potential suppliers?

How do delivery elements incentivise and influence suppliers?

Are clear and stable relationships in place for each primary supplier?

\section{S4.3 Delivering Projects and Services}

Are there clear mechanisms in place for each delivery element (Programme, Project, Service) to deliver against

'User' requirements?

How is delivery communicated to 'Users'?

What mechanisms are in place for 'Users' to provide feedback on delivery?

\section{S4.4 Managing Delivery Performance and Risk}

Are appropriate mechanisms in place to enable effective management and decision making within delivery

elements (Programme, Project and Service)?

Supported by levels of delegation and autonomy?

How do delivery elements demonstrate compliance with mandated requirements? 


\section{Appendix B - Participant Feedback Questionnaire}

This appendix contains the participant feedback questionnaire that was adapted from the work of Midgley et al. (2013) for use in our context.

\section{PARTICIPANT FEEDBACK QUESTIONAIRRE}

The aim of this questionnaire is to capture participant perspectives on research conducted by Dstl in order to inform the continuous development of research methods and practices. The responses will not be used to evaluate the performance of the research team and responses will be anonymised. Therefore full and frank feedback is encouraged.

\section{Purpose:}

1. What was the purpose of this research as expressed by the research team?

2. What was your purpose for engaging with this research?

3. Were there conflicting purposes (e.g. between participants and/or between participants and researchers), and (if so) what were the effects?

\section{Context:}

4. What key perspectives and/or issues did you bring, and what impact (if any) did these have?

5. What key perspectives and/or issues did others bring, and what impact (if any) did these have?

6. How did you and/or others perceive the researchers?

7. Were there significant processes of marginalisation or exclusion of people and/or issues, and (if so) what impact did these have?

\section{Research Methods}

8. How effective were the method(s) at facilitating participant contributions, and why?

9. How effective were the method(s) at helping participants to structure and/or solve problems, and why?

10. How competent did the research team appear to be in the method(s) used?

11. What aspects could the research team have improved upon?

\section{Outcomes}

12. How well did this research satisfy the expressed purpose and/or other purposes?

13. What immediate plans, actions or changes were achieved as a direct result of the research, and why?

14. What longer-term outcomes have been achieved, and can these be linked back to the research?

15. What outcomes (positive and negative) were unanticipated? 


\section{Appendix C - Hierarchical Process Modelling for Problem Structuring}

Hierarchical Process Modelling (HPM) begins with stakeholders agreeing a top-level process analogous to the construction of a root definition in Soft Systems Methodology (SSM). This process is similar to the Transformation of a root definition in SSM although in HPM this would be considered the purpose of the system to be modelled. The modelling paradigm is consistent with the soft systems view of (Checkland \& Holwell, 2004).

Once stakeholders have agreed the transformational goal or purpose of the system, modelling is conducted in facilitated group model building sessions of the sort analysed in this paper. The facilitator leads the participants through a language game of answering 'how' questions in order to decompose the top-level process into more detail as stakeholders build a shared understanding of how the transformation is to be achieved. At any time the dual of the 'how' question - 'why' - can be asked by participants to move back up the hierarchy to understand context. Challenging the top-level process is also allowable in the language game enabling questions about system boundary. Synergies across system boundary can thus be explored by further 'how' exploration of processes outside the original system being modelled.

Part of the language game entails imposing a strict grammatical form for process descriptions; they must be gerunds to enforce both a sense of doing and of a continuous present. A significant benefit from this rule is that it allows objects to enter the system model as processes. For example a vehicle such as a car could be modelled as the process <transporting passenger $>$, deferring the fulfilment of 'how' (a car or alternative mode of transport) to later in the modelling process or even postponed indefinitely if it does not really matter.

Whilst the visual representation of an HPM is, as the name states, hierarchical, the 'how' branches descending from a process are better thought of as being 'part-of' the higher-level process. A process in HPM can thus be thought of as a holon. Once participants in the modelling process have sufficient understanding of their transformational system the facilitator leads them into a new phase of modelling, that of assessing performance.

Having modelled a transformational system as an HPM it is possible to ask the question "how well are the processes performing?" HPM uses a novel method of expressing beliefs about process performance as interval numbers, which can express tri-valued statements of i) performing well (green), ii) don't know (white), and iii) not performing well (red). The inclusion of a don't know representation enables explicit capture of epistemic uncertainty (Helton \& Burmaster, 1996). These assessments of process performance by stakeholders are colloquially known as "Italian Flags". 
Whilst the original design of HPM used strict mathematical propagation of evidence to ascertain overall process performance (Hall, Blockley, \& Davis, 1998; Marashi, Davis, \& Hall, 2008) in this use of HPM as a PSM the Italian Flag is only used as a means to identify processes that are performing badly (flags that are mostly red), or there is a high degree of uncertainty (flags that are mostly white). The movement towards agreeing action to improve is thus one of identifying processes to fix (red) or find-out (white).

An extra stage that can be carried with the stakeholders is to use an argumentation phase based on ideas of dialogue mapping and Issue Based Information Systems (IBIS) (Conklin, 2003, 2006; De Liddo, 2010; Kunz \& Rittel, 1970), where processes with poor performance or high uncertainty are further resolved into the Issues causing such, the possible Options for resolution, and the Arguments for and against. Naturally, these steps can be broken arbitrarily into a number of different workshops as time and stakeholder availability allow.

\section{Additional References}

Checkland P and Holwell S (2004). "Classic" OR and "soft" OR - an asymmetric complementarity. In M. Pidd (Ed.), Systems Modelling: Theory and Practice. John Wiley \& Sons, Ltd : Chichester. Conklin J (2003). Dialogue Mapping: Reflections on an Industrial Strength Case Study. In. Kirschner

P A, Buckingham Shum S and Carr C (Ed.), Visualizing Argumentation. Springer-Verlag: London.

Conklin J (2006). Dialogue mapping: building shared understanding of wicked problems. Wiley: Chichester.

De Liddo A and Buckingham Shum, S (2010). Cohere: A Prototype for Contested Collective Intelligence. Paper presented at the Workshop on Collective Intelligence In Organizations: Toward a Research Agenda. ACM Conference on Computer-Supported Cooperative Work, Savannah, GA, USA.

Helton J C and Burmaster D E (1996). Guest editorial: Treatment of aleatory and epistemic uncertainty in performance assessments for complex systems. Reliability Engineering and System Safety 54(2-3): 91-94.

Kunz W and Rittel H W J (1970). Issues as Elements of Information Systems: Studiengruppe für Systemforschung, Heidelberg, Germany. 